\title{
Managing Heart Disease in Pregnancy
}

Authors:

Disclosure:

Received:

Accepted:

Keywords:

Citation:
Summit Dev Bloria, ${ }^{1}$ Ritika Bajaj,, ${ }^{*}$ Ankur Luthra, ${ }^{1}$ Rajeev Chauhan'

1. Post Graduate Institute of Medical Education and Research (PGIMER), Chandigarh, India

2. Jindal IVF and Sant Memorial Nursing Home, Chandigarh, India

*Correspondence to zazzydude979@gmail.com

The authors have declared no conflicts of interest.

18.06.19

25.10.19

Cardiomyopathy, management, peripartum, preconceptional counselling, pregnancy, valvular diseases.

EMJ. 2020;5[1]:58-66.

\section{Abstract}

Cardiac disease is an important cause of mortality in pregnancy. It has the potential to remain undiagnosed and may present with cardiovascular decompensation during pregnancy, at the time of delivery, or immediately postpartum. It can have long-term implications to the life of the affected women and their families. This review summarises the current knowledge of the incidence, prevalence, and management of pregnancy-related cardiovascular disease in women presenting preconceptionally or during pregnancy.

\section{INTRODUCTION}

Cardiovascular diseases complicate approximately $0.2-4.0 \%$ of pregnancies. ${ }^{1}$ Their incidence is increasing, and they are already the most common cause of maternal death in the UK. ${ }^{2}$ These patients are at higher risk of mortality as well as increased morbidity and thus need special care during the period of pregnancy.

\section{PREGNANCY CHANGES IN MAJOR BODY ORGAN-SYSTEMS}

Several changes during pregnancy in a normal patient can occur:

$>$ Central nervous system changes: decreases in minimum alveolar concentration ${ }^{3}$ and local anaesthetic requirement during neuraxial blocks. ${ }^{4}$
> Respiratory system changes: development of upper airway oedema, decreases in functional residual capacity, and increases in ventilation. ${ }^{5}$

> Cardiovascular system changes: increases in blood volume, cardiac output (CO), and development of supine hypotension syndrome. ${ }^{6,7}$

> Gastrointestinal system changes: altered gastric emptying, increased gastrin secretion, and increased likelihood of gastroesophageal reflux. ${ }^{8}$

> Renal and hepatic changes: increased glomerular filtration rate and raised levels of liver enzymes. ${ }^{9}$

These changes are usually well-tolerated in normal patients; however, in patients with pre-existing disorders of body systems these changes can cause acute decompensation of disease status and can be catastrophic. 
In this review the management of pregnant patients with cardiac disease is discussed, beginning with the discussion of the cardiovascular system changes in normal pregnancy followed by management of specific cardiac diseases during pregnancy.

\section{LITERATURE SEARCH AND SELECTION}

For the literature search, an electronic search in Google Scholar, PubMed, and Cochrane Databases for original and review articles on cardiac disease in pregnancy until March 2019 was performed. Only full text articles were included.

\section{CARDIOVASCULAR CHANGES IN NORMAL PREGNANCY}

The changes in the cardiovascular system evolve as a pregnancy advances.

\section{Changes in the Left Ventricle}

The left ventricular (LV) mass increases during pregnancy..$^{10}$ The LV diastolic function increases during the first two trimesters and falls in the third trimester. ${ }^{10}$ Pre-eclampsia patients and patients with multiple gestation show a greater increase in LV mass. ${ }^{11,12}$

\section{Changes in Cardiac Output}

Increased levels of the hormone progesterone cause peripheral vasodilation leading to a decrease in systemic vascular resistance. As a response to decreased systemic vascular resistance, $\mathrm{CO}$ increases progressively as the duration of pregnancy increases. Although an increase in both heart rate and stroke volume contribute to increased $\mathrm{CO}$, the increase is predominantly a result of augmented stroke volume. ${ }^{6}$ By 8 weeks, CO has increased by $20 \%$ and then up to $50 \%$ by 20 weeks. ${ }^{13}$ The CO further increases by $15 \%$ during the first stage of labour. ${ }^{14,15}$ After delivery of the baby, autotransfusion of approximately 300-500 $\mathrm{mL}$ of blood from uterine circulation to maternal circulation occurs. This can lead to an increase in CO of up to $60-80 \%$ during the second stage of labour. ${ }^{16}$ In case of twin pregnancies, there is an additional $10-20 \%$ increase in $\mathrm{CO}^{17}$

\section{Changes in Blood Pressure}

Systolic, diastolic, and mean blood pressure decrease during mid-pregnancy and return toward baseline as the pregnancy approaches term..$^{18}$ The mean ( \pm 2 standard deviations) systolic blood pressure and diastolic blood pressure in women who have never given birth at 12 weeks have been described to be $112.1 \mathrm{mmHg}$ (88.6$135.5 \mathrm{mmHg}$ ) and $65.4 \mathrm{mmHg}(48.9-81.9 \mathrm{mmHg})$, respectively. ${ }^{19}$ It has been suggested that a raised mid-trimester mean arterial BP is predictive of subsequent development of pregnancy-induced hypertension/pre-eclampsia. ${ }^{20}$

\section{Total Blood Volume Changes}

Pregnancy is also characterised by an increase in total blood volume. This increase begins as early as 6 weeks of pregnancy and is rapid during the first half of pregnancy, after which the increase in blood volume progresses at a slower rate. ${ }^{21,22}$ There is also an increase in red blood cell mass during pregnancy; however, this increase is to a lesser extent compared with the increase in blood volume. Hence, there is haemodilution and resultant development of 'physiological anaemia of pregnancy'.

\section{ECG Changes}

ECG changes during pregnancy consist of nonspecific ST-segment and T-wave changes. Repolarisation abnormalities are absent in normal pregnancies. LV mass increases during normal pregnancy. ${ }^{10}$

\section{ASSESSMENT OF PREGNANCY RISK}

All female cardiac patients should undergo a preconception counselling, which should include a detailed discussion of the risk of pregnancy. There are numerous important issues to be considered during this counselling:

$>$ Evaluation of present cardiac status using history, clinical exam, and relevant investigations.

> Optimisation of cardiac status.

$>$ Changes in medication regimen, e.g., replacing teratogenic drugs with nonteratogenic drugs. 
$>$ Discussion about maternal life expectancy and long-term effects of pregnancy on their heart.

$>$ Genetic screening in patients with inherited disorders.

\section{CARPREG RISK SCORE}

Siu et al. ${ }^{23}$ had proposed the Cardiac Disease in Pregnancy (CARPREG) Risk Score to estimate a woman's cardiac risk during pregnancy. During the calculation of the total score, one point is assigned for each of the four risk factors:

\section{A history of cardiac event or arrhythmia,}

2. New York Heart Association (NYHA) functional class greater than II or cyanosis,

3. left-heart obstruction (mitral valve area $<2.0$ $\mathrm{cm}^{2}$, aortic valve area $<1.5 \mathrm{~cm}^{2}$, or LV outflow tract gradient $>30.0 \mathrm{mmHg}$ ), and

\section{LV ejection fraction (LVEF) $<0.40$.}

A score of 0 points confers a $5 \%$ risk of cardiac complications, whereas scores of 1 or 2 points denote a $27 \%$ and $75 \%$ risk, respectively. Post CARPREG, many such risk stratification models have been suggested by other bodies, prominent among them being World Health Organization (WHO) classification, ZAHARA risk score, European Society of Cardiology (ESC) guidelines, plus more. To determine the risk of pregnancy in cardiac patients, WHO has classified patients into four pregnancy risk classes (Classes I-IV) as determined by their medical condition (Box 1).

\section{MANAGEMENT OF CONGENITAL HEART DISEASES}

\section{Atrial Septal Defect}

Patients with unrepaired atrial septal defect (ASD) should have their right ventricular function assessed. It has been suggested that pregnant women with an ASD are more likely to develop supraventricular and ventricular arrhythmias than nonpregnant women. ${ }^{24}$ In patients with unrepaired ASD the risk of paradoxical air embolism is present. Patients with repaired ASD can be managed as normal patients; however, ASD (both repaired or unrepaired) patients with pulmonary arterial pressure $>40 \mathrm{mmHg}$ are considered as high-risk patients and preload should be maintained.

\section{Ventricular Septal Defects}

Pregnancy is usually well-tolerated in patients with ventricular septal defects. The only risk from a small haemodynamically insignificant ventricular septal defect is of endocarditis, and antibiotics should be administered at the time of instrumental or complicated deliveries. However, patients with raised pulmonary arterial pressures $(>40 \mathrm{mmHg}$ ) are considered high risk. Additionally, women with either unoperated ventricular septal defects or with late repair may have associated pulmonary vascular disease.

\section{Patent Ductus Arteriosus}

Usually pregnancy is well-tolerated in patent ductus arteriosus patients with complications being rare. $^{25}$ However, in patients who have developed reversal of shunt (Eisenmenger syndrome), pregnancy is not recommended because of the risk of death reaching as high as $40-50 \%{ }^{26}$

\section{Transposition of the Great Arteries}

There are two types of transposition of the great arteries (TGA): D-TGA, in which only origins of aorta and pulmonary trunk are transposed; and L-TGA, in which the morphological left and right ventricles with their corresponding atrioventricular valves are also transposed, in addition to aorta and pulmonary trunk. D-TGA patients undergo either arterial (Jatene or Rastelli) or atrial switch (Senning or Mustard) operations. The patients who have undergone arterial switch operation are predisposed to develop myocardial ischaemia (because the coronary arteries are reimplanted during these procedures), while patients with atrial switch can be afflicted by pulmonary hypertension, atrial arrhythmias (as a result of atrial scarring), tricuspid regurgitation, plus more. ${ }^{27}$ In these patients, a cardiac evaluation and ECG/MRI are recommended prior to planned pregnancy. Pregnancy is usually well-tolerated in NYHA Class I-Il patients post-Mustard procedure. ${ }^{28}$ Patients with L-TGA usually have uneventful pregnancies.

\section{Ebstein's Anomaly}

Ebstein's anomaly is a congenital heart defect in which the septal and posterior leaflets of the tricuspid valve are displaced towards the apex of the right ventricle of the heart. 


\begin{tabular}{|c|c|}
\hline $\begin{array}{l}\text { No detectable increased risk of materna } \\
\text { no, or mild, increased risk of morbidity. }\end{array}$ & $\begin{array}{l}\text { 1. Uncomplicated small or mild pulmonary stenosis, } \\
\text { patent ductus arteriosus, mitral valve prolapse. } \\
\text { 2. Successfully repaired simple lesions (ASD, VSD, PDA, } \\
\text { anomalous pulmonary venous drainage). } \\
\text { 3. Isolated atrial or ventricular ectopic beats. }\end{array}$ \\
\hline $\begin{array}{l}\text { Class II } \\
\text { Small increased risk of maternal mortality or moderate } \\
\text { increase in morbidity. }\end{array}$ & $\begin{array}{l}\text { 1. Unoperated ASD or VSD. } \\
\text { 2. Repaired tetralogy of Fallot. } \\
\text { 3. Most arrhythmias. }\end{array}$ \\
\hline $\begin{array}{l}\text { Class II-III } \\
\text { Significantly increased risk of maternal mortality or } \\
\text { severe morbidity. Expert counselling required. } \\
\text { If pregnancy is decided upon, intensive specialist cardiac } \\
\text { and obstetric monitoring needed throughout pregnancy, } \\
\text { childbirth, and the puerperium. }\end{array}$ & $\begin{array}{l}\text { 1. Mild left ventricular impairment. } \\
\text { 2. Hypertrophic cardiomyopathy. } \\
\text { 3. Native or tissue valvular heart disease not considered } \\
\text { WHO I or IV. } \\
\text { 4. Marfan syndrome without aortic dilatation or aorta } \\
\text { < } 45 \mathrm{~mm} \text { in aortic disease associated with bicuspid } \\
\text { aortic valve. } \\
\text { 5. Repaired coarctation. }\end{array}$ \\
\hline $\begin{array}{l}\text { Class III } \\
\text { Significantly increased risk of maternal mortality or } \\
\text { severe morbidity. Expert counselling required. } \\
\text { If pregnancy is decided upon, intensive specialist cardiac } \\
\text { and obstetric monitoring needed throughout pregnancy, } \\
\text { childbirth, and the puerperium. }\end{array}$ & $\begin{array}{l}\text { 1. Mechanical valve. } \\
\text { 2. Systemic right ventricle. } \\
\text { 3. Fontan circulation. } \\
\text { 4. Cyanotic heart disease (unrepaired). } \\
\text { 5. Other complex congenital heart disease. } \\
\text { 6. Aortic dilatation } 40-45 \mathrm{~mm} \text { in Marfan syndrome. } \\
\text { 7. Aortic dilatation } 45-50 \mathrm{~mm} \text { in aortic disease } \\
\text { associated with bicuspid aortic valve. }\end{array}$ \\
\hline $\begin{array}{l}\text { Class IV } \\
\text { (Pregnancy contraindicated) } \\
\text { Extremely high risk of maternal mortality or severe } \\
\text { morbidity; pregnancy contraindicated. } \\
\text { If pregnancy occurs termination should be discusse } \\
\text { pregnancy continues, care as for Class III. }\end{array}$ & $\begin{array}{l}\text { 1. Pulmonary artery hypertension of any cause. } \\
\text { 2. Severe systemic ventricular dysfunction (LVEF <30\%, } \\
\text { NYHA III-IV). } \\
\text { 3. Previous peripartum cardiomyopathy with any residual } \\
\text { impairment of left ventricular function. } \\
\text { 4. Severe mitral stenosis, severe symptomatic } \\
\text { aortic stenosis. } \\
\text { 5. Marfan syndrome with aorta dilated }>45 \mathrm{~mm} \text {. } \\
\text { 6. Aortic dilatation }>50 \mathrm{~mm} \text { in aortic disease associated } \\
\text { with bicuspid aortic valve. } \\
\text { 7. Native severe coarctation. }\end{array}$ \\
\hline
\end{tabular}

ASD: atrial septal defect; LVEF: left ventricular ejection fraction; NYHA: New York Heart Association; PDA: patent ductus arteriosus; VSD: ventricular septal defect; WHO: World Health Organization.

Patients with preserved ventricular function tolerate pregnancy well, whereas those with associated ASD and cyanosis have an increased risk for fetal loss. ${ }^{29}$ Additionally, arrhythmias are very common in these patients. Severe Ebstein's anomaly should be repaired prior to pregnancy.

\section{Tetralogy of Fallot}

It is rare to have tetralogy of Fallot patients survive to adulthood without corrective surgery. Women with repaired tetralogy of Fallot and well compensated haemodynamic function tolerate pregnancy well, though they remain at risk for atrial and ventricular arrhythmias. However, the presence of pulmonary hypertension, right ventricular dysfunction, right ventricular dilation, and pulmonic regurgitation predisposes these patients to adverse peripartum complications such as arrhythmias and right-sided heart failure.

\section{Fontan Circulation}

In Fontan surgery, the right ventricle is bypassed and venous blood flows directly from vena cavae to pulmonary arteries. Fontan operation is performed for tricuspid or pulmonic atresia, as well as other anomalies with a single ventricle. These patients are predisposed to the development of thrombus formation (due to slow flow of venous blood) and arrhythmias (as a result of surgical scar tissue in the atrium). ${ }^{30,31}$ 


\section{MANAGEMENT OF ACUTE CORONARY SYNDROME}

Acute coronary syndrome (ACS) includes ST elevation myocardial infarction (STEMI), non-STEMI, and unstable angina. ACS during pregnancy is rare, with an incidence of 1 in 16,000 deliveries. ${ }^{32}$ The classical presentation of ACS presenting as crushing chest pain with radiation to neck and arm is uncommon, and even in those patients who present with these classical features, often these symptoms are attributed to dyspepsia and changes of normal pregnancy. Hence diagnosis may be difficult.

STEMI should be a clinical diagnosis based on the presence of pain with typical ECG changes (either a $1 \mathrm{~mm}$ of ST elevation in contiguous leads corresponding to an arterial territory or new left bundle branch block). All patients with a history of pain that may be a result of cardiac ischaemia should have a prompt 12-lead ECG.

Diagnosing non-STEMI will be based on the presence of elevated cardiac troponin levels (or a documented rise and fall) in the setting of pain compatible with cardiac ischaemia. Unstable angina may present similarly to non-STEMI but without an elevated troponin level. Often these patients are still at high risk of future events or development of more extensive ACS if not managed appropriately.

In patients who are presenting with stable symptoms (symptoms or exertion), noninvasive investigations of cardiac ischaemia are the preferred management. Exercise testing is safe in pregnancy provided the patient is not having obstetric complications such as per vaginal bleeding or significant placenta praevia. The disadvantage of this test, however, is the high false-positive rate in the nonpregnant woman.

\section{In patients with STEMI}

> Oxygen supplementation.

> Aspirin (300 mg) and clopidogrel (300 mg).

$>$ Appropriate intervention in the form of coronary angiography, emergency coronary intervention, and thrombolysis should not be withheld in the pregnant or puerperal woman. ${ }^{33}$ The first choice for treatment of ACS in pregnant women is percutaneous coronary intervention (balloon angioplasty with or without a stent). ${ }^{34}$

\section{In patients with Non-STEMI/Unstable Angina}

Low-risk patients should be managed medically (aspirin, clopidogrel, low-molecular-weight heparin, other antianginal agents), while high-risk patients should preferably undergo angiography and, if needed, coronary stenting.

\section{MANAGEMENT OF VALVULAR HEART DISEASES}

\section{Mitral Stenosis}

Even patients with mild mitral stenosis can develop arrythmias and pulmonary oedema during pregnancy. When possible, preconception treatment of symptomatic moderate or severe mitral stenosis is preferred, percutaneous balloon mitral valvuloplasty being the procedure of choice. ${ }^{35}$ For patients who require percutaneous valvuloplasty during pregnancy, the procedure is ideally performed after 12-14 weeks gestation in order to minimise fetal radiation exposure during the period of organogenesis. If the patient can be stabilised with medical management, delaying the procedure to 26-30 weeks gestation will help reduce the risk for preterm birth. Open surgical mitral valve commissurotomy is another treatment option but is associated with higher rates of fetal mortality than percutaneous valvuloplasty (38\% versus $5 \%$, respectively).

Medical management includes administration of $\beta$-blockers, aimed at slowing the heart rate and thereby lengthening the diastolic filling period. Atrial fibrillation and atrial flutter should be treated promptly with rate control, and early cardioversion should be considered. Furthermore, systemic anticoagulation is recommended for the duration of pregnancy and postpartum along with diuretics and bed rest.

\section{Mitral Regurgitation}

Mitral regurgitation is usually well-tolerated during pregnancy, but ECG is recommended because chronic mitral regurgitation may be associated with LV dysfunction. If valve intervention is indicated in women of childbearing age who have 
severe mitral regurgitation, valve repair should be offered when possible.

\section{Aortic Stenosis}

Mild and moderate aortic stenosis are associated with favourable pregnancy outcomes. ${ }^{36,37}$ Severe aortic stenosis patients are more predisposed to develop cardiac complications as well as the need for cardiac intervention. Balloon valvuloplasty is preferred if technically possible because it is reported to have a smaller risk of fetal loss, and even if the benefit is short lasting, it may be sufficient to allow successful completion of the pregnancy.

\section{Aortic Regurgitation}

Chronic, moderate, or even severe aortic regurgitation is usually well-tolerated if LV function is preserved; nevertheless, women with severe aortic regurgitation are at a risk of developing pulmonary oedema and arrhythmias during pregnancy. Valve replacement during pregnancy for treatment of aortic regurgitation is rarely required.

\section{Pregnant Patients with Prosthetic Valves}

These patients have increased chances of morbidity and mortality. ${ }^{38}$ In the subset of 134 women with bioprosthetic valves in the Registry of Pregnancy and Cardiac Disease (ROPAC) study, heart failure complicated $8.2 \%$ of pregnancies in women with bioprosthetic valves, endocarditis and thrombotic complications in $<1.0 \%$, and haemorrhagic complications in $5.1 \%$ of pregnancies. ${ }^{38}$ Prosthetic heart valves can either be bioprosthetic or mechanical; the former are often recommended in young females because of a lower risk of thromboembolism and anticoagulation. However, bioprosthetic valves tend to deteriorate early, predisposing to repeated surgeries.

In patients with mechanical prosthetic heart valves, the current American Heart Association (AHA)/American College of Cardiology (ACC) guidelines suggest continuing warfarin in the first trimester if the daily warfarin dose is $\leq 5 \mathrm{mg}$, after patient information and consent. In women whose daily warfarin dose is $>5 \mathrm{mg}$, and for those who consent against taking warfarin in the first trimester, it may be discontinued between Weeks 6 and 12 and replaced with either weight-adjusted twice-daily low-molecular-weight heparin or an intravenous infusion of unfractionated heparin. Warfarin is restarted along with aspirin $75 \mathrm{mg}$ in the second and third trimester until 36 weeks of gestation. Overall, pregnancy in women with mechanical prosthetic heart valves is high risk, and the safest option is not to become pregnant at all.

\section{Infective Endocarditis in Pregnancy}

Infective endocarditis is a rare, potentially life-threatening complication. Maternal and fetal mortality rates are both high. ${ }^{39}$ The AHA guidelines on the prevention of endocarditis and the ESC guidelines on the management of cardiovascular diseases during pregnancy do not recommend antibiotic prophylaxis at the time of delivery. If infective endocarditis is diagnosed, antibiotic treatment should be guided by blood culture results and antibiotic sensitivities.

\section{Cardiomyopathy}

Cardiomyopathy is a congenital or acquired disease of heart muscle. Congenital cardiomyopathy can be inherited in an autosomal dominant, autosomal recessive, X-linked dominant, $X$-linked recessive, or mitochondrial manner. Various types of cardiomyopathies exist:

\section{Hypertrophic Cardiomyopathy}

In hypertrophic cardiomyopathy, abnormal thickening of heart muscles occurs, rendering the heart muscle stiff and noncompliant. These patients are unable to sufficiently increase their stroke volume as a result of outflow obstruction in conjunction with the small stroke volume due to a small LV cavity size. Patients may be asymptomatic or present with palpitations, breathlessness, or arrhythmias.

Patients with hypertrophic cardiomyopathy are at risk from atrial and ventricular arrhythmia, pulmonary oedema, and increasing outflow tract obstruction. Atrial arrhythmia, especially atrial fibrillation from left atrial dilatation, is common and can cause thromboembolism. Normally, atria contribute around 10-30\% of ventricular filling, but in hypertrophic cardiomyopathy patients it may increase to $50 \%$ of total ventricular filling. Hence restoring sinus rhythm promptly is imperative. 


\section{Dilated Cardiomyopathy}

Dilated cardiomyopathy can be primary or secondary to myocarditis, alcohol or other toxins, endocrine and autoimmune disorders, and nutritional factors. Breathlessness, fatigue, exercise intolerance, and fluid retention are common symptoms. Pregnancy in women with dilated cardiomyopathy is associated with adverse outcomes, especially in those with significantly impaired LV function (moderate or severe LV systolic dysfunction, EF <45\% on ECG). Assessment of LV function and exercise tolerance is important in these patients preconceptionally. If the patient is being treated with heart failure medication known to have teratogenic effects, such as angiotensin-converting enzyme inhibitors or angiotensin receptor blockers, they should be stopped prior to conception. If LV function then deteriorates even before pregnancy, the patient should be advised against pregnancy. Thereafter also, ECG should be performed at regular intervals to determine if LV function declines as a consequence of their withdrawal. $\beta$-blockers should be continued during pregnancy and postpartum. Other drugs used are diuretics (to manage fluid status) and nitrates or hydralazine (to reduce preload). Pregnancy may have to be terminated at any duration of gestation if LV function deteriorates.

\section{Peripartum Cardiomyopathy}

The Working Group on Peripartum Cardiomyopathy (PPCM) of the ESC recently updated the operational definition of PPCM, defining PPCM as cardiomyopathy with reduced $E F$, usually $<45 \%$, presenting toward the end of pregnancy or in the months after delivery in a woman without previously known structural heart disease. ${ }^{40}$ PPCM is associated with significant morbidity and mortality. ${ }^{41}$ The exact aetiology of PPCM remains unknown; however, fetal microchimerism, increased cardiomyocyte apoptosis, hormonal insults, genetics, autoimmune inflammation and myocarditis with and without viral triggers, and a familial association have been proposed. ${ }^{42}$ Most cases present in the first week following delivery. ${ }^{43}$ Increasing age, multiple gestations, race, and pre-eclampsia have been found to be associated with development of PPCM. ${ }^{44}$ ECG usually shows dilatation of LV, LV systolic dysfunction, right ventricular and biatrial enlargement, mitral and tricuspid regurgitation, and pulmonary hypertension. ${ }^{44,45}$

Digitalis is used to augment systolic function and is safe, although its role in the management of systolic heart failure has been questioned. ${ }^{46}$ Anticoagulation may be added and continued postpartum if the LVEF remains $<30 \%$ for prevention of thromboembolic complications. Angiotensin-converting enzyme inhibitors should be started as soon as possible after delivery, and are safe for breastfeeding. Bromocriptine, a dopamine receptor agonist and prolactin inhibitor, has showed improvements in LV recovery. ${ }^{47}$ Cardiac assist devices and implantable cardiac defibrillators have been used in patients with severe depression of LV function and persistent arrhythmias. ${ }^{48,49}$

\section{Restrictive Cardiomyopathy}

Restrictive cardiomyopathy can affect both sides of the heart and is characterised by small, stiff ventricles with abnormal relaxation. As a result, diastolic filling is impaired, which in turn causes small stroke volumes and a low $\mathrm{CO}$, despite an often preserved systolic function.

\section{Pulmonary Hypertension}

Pulmonary hypertension (PAH) is defined as an increase in mean pulmonary arterial pressure $\geq 25 \mathrm{mmHg}$ at rest.50 In patients with congenital heart disease, PAH most commonly occurs as a result of long-term left-to-right shunting, leading to increased pulmonary flow that eventually causes high PVR, resulting in reversed or bidirectional shunts, which is referred to as Eisenmenger syndrome.

Women with PAH should be strongly counselled against pregnancy at the time the diagnosis of $\mathrm{PAH}$, and advice on appropriate contraception should be provided. Pulmonary vasodilators, such as iloprost, inhaled nitric oxide, endothelin receptor antagonists, and phosphodiesterase inhibitors, have been used in these patients and have improved outcomes to some extent. ${ }^{51}$

\section{Aortic Dissection}

Aortic dissection is a particular risk in women with Marfan syndrome. $\beta$-blockers should be continued or started in pregnant patients with Marfan syndrome who have aortic dilatation or 
hypertension because they have reduce the rate of aortic dilatation. ${ }^{52}$ Monitoring during pregnancy will normally include regular (e.g., every 4-8 weeks) transthoracic ECG to assess aortic root diameter. The timing of delivery will be dependent on the root diameter and the rate of dilatation, as well as any other complicating factors.

\section{COMMON ARRYTHMIAS DURING PREGNANCY}

Cardiovascular changes during pregnancy predispose the development of new onset arrhythmias as well as recurrence in patients with a history of arrhythmias. ${ }^{53}$ Ectopic beats are said to be common during pregnancy and usually do not require any treatment. ${ }^{54}$

Patients without any history of heart disease usually present with atrioventricular nodal reentrant tachycardia. ${ }^{55}$ Direct current cardioversion has been found to be safe in all stages of pregnancy; however, fetal monitoring is advised during cardioversion.56 In haemodynamically stable patients, intravenous adenosine is commonly used for termination of atrioventricular node dependent supraventricular tachycardia. Catheter ablation therapy is generally contraindicated due to high radiation exposure. Patients presenting with symptomatic bradycardia and a heart rate $<50$ beats per minute are candidates for permanent pacemaker insertion. ${ }^{57}$

\section{RADIATION EXPOSURE DURING PREGNANCY}

The effects of in utero radiation exposure include intrauterine growth retardation, childhood cancers, mental retardation, and fetal death. The gestational age, radiation dose, and repair mechanisms determine the final effect of the radiation on the fetus. A dose $<0.05 \mathrm{~Gy}$ does not cause any malignancy related health issues. ${ }^{58}$

\section{CONCLUSION}

The spectrum of cardiac disease has changed over time, with rheumatic disease becoming uncommon while congenital heart disease becomes more common. As newer and better treatment modalities for the management of cardiac diseases emerge, the number of cardiac disease patients becoming pregnant also continues to increase.

Pregnancy may predispose cardiac disease patients to many complications, some of which may be life threatening. While the risk may be so high in certain disease states that pregnancy should be altogether avoided, successful outcomes are possible in other cases provided close co-ordination and collaboration is maintained between all the members of the treating team.

\section{References}

1. Regitz-Zagrosek et al. Cardiovascular diseases in pregnancy. Dtsch Arztebl. 2011;108(16):267-73.

2. Royal College of Obstetricians and Gynaecologists. Why mothers die 1997-1999, the confidential enquiries into maternal deaths in the United Kingdom. 2001. Available at: https://elearning.rcog.org.uk/sites/ default/files/Gynaecological\%20 emergencies/CEMACH_Why Mothers_Die_OO-02_2004.pdf. Last accessed: 25 October 2019.

3. Chan MT et al. Minimum alveolar concentration of halothane and enflurane are decreased in early pregnancy. Anesthesiology. 1996;85(4):782-6.

4. Flanagan $\mathrm{HL}$ et al. Effect of pregnancy on bupivacaine-induced conduction blockade in the isolated rabbit vagus nerve. Anesth Analg. 1987;66(2):123-6.
5. Norwitz ER et al. "Pregnancy-induced physiologic alterations," Dildy GA et al. (eds.), Critical Care Obstetrics (2004) $4^{\text {th }}$ edition, New Jersey: Blackwell Science, pp.19-42.

6. Robson SC et al. Serial study of factors influencing changes in cardiac output during human pregnancy. Am J Physiol. 1989;256(4 Pt2):H1060-5.

7. Ueland K. Maternal cardiovascular dynamics. VII. Intrapartum blood volume changes. Am J Obstet Gynecol. 1976;126(6):671-7.

8. Whitehead EM et al. An evaluation of gastric emptying times in pregnancy and the puerperium. Anaesthesia. 1993;48(1):53-7.

9. Cheung KL, Lafayette RA. Renal physiology of pregnancy. Adv Chronic Kidney Dis. 2013;20(3):20914.

10. Kametas NA et al. Maternal left ventricular mass and diastolic function during pregnancy. Ultrasound Obstet Gynecol. 2001;18(5):460-6.

11. Kametas NA et al. Maternal cardiac function in twin pregnancy. Obstet Gynecol. 2003; 102(4):806-15.

12. Borghi $\mathrm{C}$ et al. Relationship of systemic hemodynamics, left ventricular structure and function, and plasma natriuretic peptide concentrations during pregnancy complicated by preeclampsia. Am J Obstet Gynecol. 2000;183(1):140-7.

13. Meah VL et al. Cardiac output and related haemodynamics during pregnancy: a series of meta-analyses. Heart. 2016;102(7):518-26.

14. Ueland K, Hansen JM. Maternal cardiovascular dynamics.III. Labor and delivery under local and caudal analgesia. Am J Obstet Gynecol. 1969:103(1):8-18. 
15. Robson $\mathrm{C}$ et al. Cardiac output during labour. Br Med J (Clin Res Ed) 1987:295(6607):1169-72.

16. Lee $\mathrm{W}$ et al. Maternal hemodynamics effects of uterine contractions by M-mode and pulsed-Doppler echocardiography. Am J Obstet Gynecol. 1989;161(4):974-7

17. Veille JC et al. Maternal cardiovascular adaptations to twin pregnancy. Am J Obstet Gynecol. $1985 ; 153(3): 261-3$.

18. Iwasaki $\mathrm{R}$ et al. Relationship between blood pressure level in early pregnancy and subsequent changes in blood pressure during pregnancy. Acta Obstet Gynecol Scand. 2002:81(10):918-25.

19. Macdonald-Wallis $C$ et al. Gestationalage-specific reference range for blood pressure in pregnancy: findings from a prospective cohort. J Hypertens. 2015;33(1):96-105.

20. Cnossen JS et al. Accuracy of mean arterial pressure and blood pressure measurements in predicting pre-eclampsia: systematic review and meta-analysis. BMJ. 2008;336(7653):1117-20.

21. Lund CJ, Donovan JC. Blood volume during pregnancy. Am J Obstet Gynecol. 1967;98(3):393-403.

22. Pritchard JA. Changes in the blood volume during pregnancy and delivery. Anesthesiology. 1965;26:393

23. Siu SC et al. Prospective multicenter study of pregnancy outcomes in women with heart disease. Circulation. 2001;104(5):515-21.

24. Gatzoulis MA et al. Atrial arrhythmia after surgical closure of atrial septal defects in adults. N Engl J Med. 1999;340(11):839-46.

25. Green NJ, Rollason TP. Pulmonary artery rupture in pregnancy complicating patent ductus arteriosus. Br Heart J. 1992;68(6):6168

26. Yentis SM et al. Eisenmenger's syndrome in pregnancy: maternal and fetal mortality in the 1990s. Br J Obstet Gynaecol. 1998;105:921-22.

27. Warnes CA. Transposition of the great arteries. Circulation. 2006;114(24):2699-709.

28. Clarkson PM et al. Outcome of pregnancy after the Mustard operation for transposition of the great arteries with intact ventricular septum. J Am Coll Cardiol. 1994:24(1):190-3.

29. Warnes CA et al. ACC/AHA 2008 guidelines for the management of adults with congenital heart disease: a report of the American College of Cardiology/American Heart Association Task Force on Practice Guidelines. Circulation. 2008;118(23):714-833.

30. Stephenson EA et al. Arrhythmias in a contemporary Fontan cohort: a revalence and clinical associations in a multicenter cross-sectional study. J Am Coll Cardiol. 2010; 56(11):890-6.

31. Drenthen $\mathrm{W}$ et al. Pregnancy and delivery in women after Fontan palliation. Heart. 2006;92(9):1290-4

32. James $\mathrm{AH}$ et al. Acute myocardial infarction in pregnancy: a United States population-based study. Circulation. 2006;113(12):156-71

33. The Confidential Enquiry into Maternal and Child Health (CEMACH). Saving Mothers' Lives: reviewing maternal deaths to make motherhood safer 2003-2005. 2007. Available at: https://www.publichealth.hscni. net/sites/default/files/Saving\%20 Mothers\%27\%20Lives\%20200305\%20.pdf. Last accessed: 25 October 2019.

34. Royal College of Obstetricians and Gynaecologists. Steer PJ et al. Heart Disease and Pregnancy. 2006. Available at: https://elearning rcog.org.uk//sites/default/files/ Cardiac\%20disease/HeartDis RCOGPress_Ch1.pdf. Last accessed: 25 October 2019.

35. Regitz-Zagrosek $\vee$ et al. ESC Guidelines on the management of cardiovascular diseases during pregnancy: the Task Force on the Management of Cardiovascular Diseases during Pregnancy of the European Society of Cardiology (ESC). Eur Heart J. 2011;32:3147-97.

36. Hameed A et al. The effect of valvular heart disease on maternal and fetal outcome of pregnancy. J Am Coll Cardiol. 2001:37(3):893-9.

37. Yap SC et al. Risk of complications during pregnancy in women with congenital aortic stenosis. Int Cardiol. 2008;126(2):240-6.

38. van Hagen IM et al. Pregnancy in women with a mechanical heart valve: data of the European Society of Cardiology Registry of Pregnancy and Cardiac Disease (ROPAC). Circulation. 2015;132(2):132-42

39. Campuzano $\mathrm{K}$ et al. Bacterial endocarditis complicating pregnancy: case report and systematic review of the literature. Arch Gynecol Obstet. 2003;268(4):251-5.

40. Sliwa $\mathrm{K}$ et al. Current state of knowledge on aetiology, diagnosis, management, and therapy of peripartum cardiomyopathy: a position statement from the Heart Failure Association of the European Society of Cardiology Working Group on Peripartum Cardiomyopathy. Eur J Heart Fail. 2010;12(8):767-78.

41. Sliwa $\mathrm{K}$ et al. Peripartum cardiomyopathy. Lancet. 2006;368(9536):687-93.

42. Ntusi NB, Mayosi BM. Aetiology and risk factors of peripartum cardiomyopathy: a systematic review. Int J Cardiol. 2009;131(2):168-79.

43. Elkayam U et al. Pregnancyassociated cardiomyopathy: clinical characteristics and a comparison between early and late presentation. Circulation. 2005;111(6):2050-5.

44. Bello $\mathrm{N}$ et al. The relationship between pre-eclampsia and peripartum cardiomyopathy: a systematic review and meta-analysis. J Am Coll Cardiol. 2013;62(18):1715-23.

45. Hibbard JU et al. A modified definition for peripartum cardiomyopathy and prognosis based on echocardiography. Obstet Gynecol. 1999;94(2):311-6.

46. Chapa JB et al. Prognostic value of echocardiography in peripartum cardiomyopathy. Obstet Gynecol. 2005;105(6):1303-8.

47. Chaggar PS et al. Is foxglove effective in heart failure? Cardiovasc Ther. 2015;33(4):236-41.

48. Haghikia A et al. Phenotyping and outcome on contemporary management in a German cohort of patients with peripartum cardiomyopathy. Basic Res Cardiol. 2013;108(4):366.

49. DeBenedetti Zunino ME et al. High rate of ventricular arrhythmias in women with peripartum cardiomyopathy and implanted cardioverter defbrillators. J Am Coll Cardiol. 2014;63(12):A313.

50. Su TW et al. Extracorporeal life support in adults with hemodynamic collapse from fulminant cardiomyopathies: the chance of bridging to recovery. ASAIO J. 2014;60(6):664-9.

51. Pieper PG et al. Pregnancy and pulmonary hypertension. Best Pract Res Clin Obstet Gynaecol. 2014;28(4):579-91.

52. Elliot CA et al. The use of iloprost in early pregnancy in patients with pulmonary arterial hypertension. Eur Respir J. 2005;26:168-73.

53. Nelson-Piercy C. "Heart disease," Nelson-Piercy C (eds.), Handbook of Obstetric Medicine (2015), $2^{\text {nd }}$ edition, Martin Dunitz: Taylor \& Francis Group.

54. Laksman Z et al. Cardiac arrhythmias during pregnancy: a clinical approach Fetal Matern Med Rev. 2011;22(2):12343.

55. Cordina R, McGuire MA. Materna cardiac arrhythmias during pregnancy and lactation. Obstet Med. 2010;3(1):8-16.

56. Adamson DL, Nelson-Piercy C. Managing palpitations and arrhythmias during pregnancy. Heart. 2007:93:1630-6.

57. Burkart TA, Conti JB. Cardiac arrhythmias during pregnancy. Curr Treat Options Cardiovasc Med. 2010;12(5):457-71.

58. Streffer $C$ et al. Biological effects after prenatal irradiation (embryo and fetus). A report of the International Commission on Radiological Protection. Ann ICRP. 2003;33(1-2):5206. 